\title{
Oil Revenues, Economic Growth and Resource Curse in Iran Economy
}

\author{
${ }^{1}$ Mohsen Mehrara*, ${ }^{2}$ Maysam Musai, ${ }^{3}$ Abbas Rezazadeh Karsalari \\ 1 University of Tehran, Tehran, Iran \\ 2Social Sciences, University of Tehran, Iran \\ ${ }^{3}$ Department of Management, Islamic Azad University Tafresh branch, Tafresh, Iran \\ *mmehrara@ut.ac.ir
}

\begin{abstract}
This paper explores the relation between oil revenues and economic growth in Iran using annual data for the period 1959-2008 to check whether this relation has a structural breakpoint effect. The results indicate the threshold level of growth rate of oil revenues above which oil revenues significantly slows growth is around $22 \%$ percent for Iran economy. In contrast, linear estimation without any allowance for threshold effects would misleadingly have us believe that an increase in the oil revenues increase the growth rate. Failure to account for nonlinearities conceal the resource curse in these countries particularly during extreme oil booms as suggested in previous studies.
\end{abstract}

Keywords: Iran Economy; oil revenues; Economic Growth; Resource Curse, threshold Model

\section{Introduction}

Since the first oil shock in 1973, almost the economic performance of Iran has been related to its natural resource wealth. The economy has experienced relatively lower per capita GDP growth and higher income inequality. This may support this hypothesis that natural resources seem to have been more of a curse than a blessing for Iran. Numerous researchers have supported the view that resource poor countries often outperform resource-rich countries (Sachs and Warner, 1995). The literature about economic growth indicates that the economists have spent much time to understand the reasons that causes economic growth. The economists have succeeded to give details about the sources of economic growth. But, until now the relation of output with the oil revenues in oil exporting countries has remained debatable. Specifically, the issue that whether oil revenues is blessing for economic growth or it is curse generates a significant debate both theoretically and empirically.

A large literature suggests that there is a 'resource curse': natural resource abundant countries tend to grow slower than resource scarce countries (Gelb, 1988; Sachs and Warner, 1995, 1997, 2001; Karl, 1997; Gylfason et al., 1999; Auty, 2001; Sala-i-Martin and Subramanian, 2003, Frederick, 2010, Pineda and Rodriguez, 2010, Thorsten, 2010). The literature offers six candidate explanations for the resource curse effect: Dutch disease, governance, conflict, excessive borrowing, inequality and volatility. However, while there is much evidence to support the curse hypothesis, the findings for oil-rich countries suggest that oil booms raise the growth of oil exporters. Spatafora and Warner (1995) investigate the impact on economic growth and development of long-run movements in the external terms of trade, with special reference to the experience of 18 oil-exporting countries. The results imply that Dutch disease effects are strikingly absent. Agriculture and manufacturing do not contract in reaction to an oil price increase. Similarly, Yang and Lam (2007) examines the relationship between oil prices and economic activities for 17 oil-rich developing countries based on cointegration analysis. Their results indicate that in the majority of cases, oil booms are followed by increases in both GDP per capita and investment. The economic development of the majority of sample countries, regardless of institutional quality, does not appear to be negatively affected by an oil boom, leaving the relation of oil revenues (or prices) with the other macroeconomic variables such as the economic growth debatable. Berument and Ceylan (2007) examine the effects of oil price shocks on a number of selected MENA economies using a structural vector autoregressive model. Their results also indicate that the effects of oil price on GDP of most oil producing countries are positive. So, the issues that whether oil resources are a curse or a blessing for economic growth in oil exporting countries warrant more attention both theoretically and empirically.

We explain this inconsistency by applying a (nonlinear) threshold model in which negative effects of oil revenues on growth may well only begin to kick in after some threshold has been breached. In this regard, recently macroeconomists have adopted an econometric technique simply by looking at the inflexion point or threshold in a nonlinear relationship so that the impact of oil revenues growth on economic 
growth could be positive up to a certain threshold level and beyond this level the effect turns to be negative. In other words, at this structural breakpoint the sign of the relationship between the two variables would switch. If so, harmful effects of oil revenues are not universal, but appear only over the "threshold" level of oil revenues. This approach can reconcile the conflict results in the literature, supporting both the view of the resource curse and blessing, that is, low revenues growth is helpful(a blessing) for economic growth but undue oil revenues, for example during a generous oil boom, is detrimental for the sustainability of such growth.

The main objective of this study is to empirically explore the relationship between oil revenues and economic growth and estimate the threshold level of oil revenues growth for a typical oil exporting country, namely Iran, based on annual data over the period 1959-2008. In other words, this paper explores an interesting policy issue of how far the oil revenues are non-detrimental for the economic growth of oil exporting countries. The remainder of this paper is organized as follows: Section 2 reviews the literature in brief. Section 3 discusses the methodology and data used to obtain the empirical findings reported in this paper. Section 4 provides empirical results. Finally, section 5 presents a summary of the main conclusions.

\section{Literature Review}

Intuitively, in an oil-dependent economy such as Iran, the exogenous increase in export revenue will release foreign exchange constraints, stimulating economic activities from both supply and demand sides. But, what is often less well understood is that this goes hand-in-hand with the real appreciation and a contraction in tradable sectors including non-oil exports, so that the natural resource blessing could become a curse. This is often taken as the main symptom of the Dutch disease (Devlin and Lewin, 2004). The revenue streams from "black gold" can finance productive physical and social investment so that the effect of oil revenues could be positive until a certain level. But after this level the effect turns to be negative, fueling unsustainable consumption booms and eventual fiscal crises. During the oil busts, with the low (or negative) growth rate of oil revenues, the oil-dependent economies suffer from undercapacity with their access to capital and intermediate imports restricted, particularly in the presence of capital market imperfections (Hausmann and Rigobon, 2003). So, more oil revenues can be a blessing during the busts or moderate booms. But when oil revenues are excessively high, the real exchange rate becomes highly overvalued. So, too much oil revenues exert a negative effect on growth, turning to be a curse. Moreover, rapid growth in public spending, which often follows extreme oil price increases, reduces spending quality and introduces entitlements, including recurrent cost commitments, which are often not sustainable in the long run. Efficiency often suffers from a high proportion of unfinished projects as well as from capital investments that cannot be effectively used because of shortages of recurrent resources. So, it seems that superfluous oil booms may have strong deterrent effects on output, while slight or moderate booms contribute to economic growth.

The important role of oil revenue in the economic growth has attracted a great deal of attention among politicians and economists. In an international context, oil price shocks may have a different impact depending on countries' sectoral compositions, their institutional structures and their economic development. Researchers have focused on analyzing the relationship between oil price changes and macroeconomic variables such as output growth, employment, wages and inflation. As we will see, the literature is still far from a consensus. In the following, we will review some selected studies. Bredin et al (2008) examined the link between oil price uncertainty and industrial production utilizing a very general and flexible empirical methodology that is based on a structural VAR modified to accommodate multivariate GARCH in mean. Their primary result is that oil price uncertainty has had a negative and significant effect on industrial production in four of the G-7 countries - Canada, France, UK and US. Impulse-response analysis suggests that, in the short-run, both positive and negative oil shocks may be contractionary. Their result helps explain why the sudden collapse in oil prices in the mid-1980's failed to produce rapid expansion in the G-7, and why the steady increases in oil prices from 2003-2007 did not induce recessions.

Nakov and Pescatori (2010) analyzed the extent to which the greater US macroeconomic stability since the mid-1980s can be accounted for by changes in oil shocks and the oil elasticity of GDP. They estimated a DSGE model and performed counterfactual simulations. They nest two popular explanations for the Great Moderation: smaller (non-oil) real shocks and better monetary policy. They found that oil played an important role in the stabilization. Around half of the reduced volatility of inflation is explained by better 
monetary policy alone, and $57 \%$ of the reduced volatility of GDP growth is attributed to smaller TFP shocks. Oil related effects explain around a third.

Mohammadi and JahanParvar (2010) studied the long-run relation and short-run dynamics between real oil prices and real exchange rates in a sample of 13 oil-exporting countries. The purpose of the study is to examine the possibility of Dutch disease in these countries. Tests of cointegration using threshold and momentum-threshold autoregressive (TAR and M-TAR) models suggest the possibility of the disease in 3out-of 13 countries-Bolivia, Mexico and Norway. For these countries, they also find that (a) oil prices have a long-run effect on the exchange rates; and (b) exchange rates adjust faster to positive deviations from the equilibrium; and (c) there is no evidence of short-run causality between real exchange rates and real oil prices in either direction. Over all, these findings suggest a weak link between oil prices and real exchange rates and thus limited evidence in favor of the Dutch disease.

Mendoza and Vera (2010) showed that oil shocks have had positive and significant effects on output growth in Venezuela during the period 1984:1-2008:3. In line with previous findings for other countries, their results suggest that the Venezuelan economy is more responsive to increases in oil prices than to unexpected decreases. Their results are robust to an alternative measure of oil price shocks derived by using Kilian's (2009) exogenous OPEC oil production shock series. Aguiar and Wen (2011) showed that fluctuations driven by self-fulfilling expectations under oil shocks are easier to occur if the cartel sets the price of oil, but the result is reversed if the cartel sets the quantity of production. These results offer a potentially interesting explanation for the decline in economic volatility (i.e., the Great Moderation) in oil importing countries since the mid-1980s when the OPEC cartel changed its market strategies from setting prices to setting quantities, despite the fact that oil prices are far more volatile today than they were 30 years ago.

Trung and Vinh (2011) examined the impact of oil prices on Vietnam's economic activity using vector autoregressive (VAR) modeling and cointegration techniques. They use monthly data for the period 19952009 and include inflation and the real effective exchange rate as additional determinants of economic activity. They find evidence of a long-run relationship between oil prices, inflation, exchange rate, and economic activity. The results suggest that both oil prices and the real effective exchange rates have strongly significant impact on economic activity. An increase in oil price or depreciation may enhance economic activity. Vietnamese economic activity is influenced more by changes of value of Vietnamese currency than the fluctuations of oil prices. Inflation has a positive impact on economic activity however its impact is not highly significant. This suggests that moderate inflation is helpful rather than harmful to economic activity.

\section{Methodology and Data}

In this section we investigate the nonlinear effects of oil revenue changes on economic activities for 13 oil-exporting countries (Algeria, Colombia, Ecuador, Indonesia, Iran, Kuwait, Libya, Mexico, Nigeria, Qatar, Saudi Arabia, United Arab Emirates and Venezuela) using five-year-averaged data over the period 19652005. Following the work of Levine and Renelt (1992), which searched for a set of robust variables to model growth and the theoretical contributions to the new growth theory literature following Romer (1990), a degree of convergence on the most appropriate empirical specification for modeling growth, has occurred ${ }^{1}$. Most models include as explanatory variables: investment, population growth, and initial per capita GDP. We include these, together with oil revenues.

To model the non-linearity of the oil revenues-growth relationship and the estimation of threshold of oil revenues this paper uses a spline technique, allowing the relationship to have a kink turning point. The equation to estimate the threshold of oil revenues growth has been considered in the following form²:

$$
G D P G R_{t}=\beta_{0}+\beta_{1} \text { OILREVGR }+\beta_{2} D_{t}(\text { OILREVGR }-K)+\beta_{3} I N V_{t}+\beta_{4} I N F_{t}+\varepsilon_{t}
$$

For a review of evidence, see Temple (1999):

2. Obviously, oil revenues-growth regressions must include other plausible determinants of growth. The variables are chosen based on empirical literature, theories of economic growth, and diagnostic tests. 
$D_{t}=\left\{\begin{array}{l}1 \text { if } \text { OILREVGR }>K \\ 0 \text { if } \text { OILREVGR } \leq K\end{array}\right.$

where GDPGR is the non oil real GDP (based on constant local currency), OILREVGR is oil revenues growth rate in real terms (taking the ratio of nominal oil revenues in US dollars to the US Producer Price Index), $K$ is the threshold level of the growth rate of oil revenues, $D_{i t}$ is a dummy variable that takes a value of one for oil revenues growth rates greater than $\mathrm{K}$ percent and zero otherwise, $I N V$ is investment as a share of GDP and INF stands for CPI inflation. The data are annual over the 1959 - 2004 periods. The source of data is the Central Bank of Iran.

The coefficient of the dummy variable $\left(\beta_{2}\right.$ ) measures the incremental effect of oil revenues growth on the economic growth when it is greater than the assumed structural break level (i.e. oil revenues growth is high) and the opposite for the coefficient of $\beta_{1}$. In other words, the coefficient of $\beta_{2}$ indicates the difference in the oil revenues effect on growth between the two sides of the structural break. In the above threshold model, the sum of the two coefficients $\left(\beta_{1}+\beta_{2}\right)$ represents the economic growth rate when the growth rate of oil revenues are higher than $k$ percent (the structural break point).

By estimating regressions for different values of $k$ which is chosen in an ascending order (i.e., $0.01,0.02$ and so on), the optimal value $k$ is obtained by finding the value that maximizes the $\mathrm{R}^{2}$ from the respective regressions. This also implies that the optimal threshold level is that which minimizes the residual sum of squares (RSS). Moreover, it is important to determine whether the threshold effect is statistically significant. In equation (1), to test for no threshold effects amount simply to testing the null hypothesis $H_{0}: \beta_{2}=0$. Under the null hypothesis, the threshold $k$ is not identified, so classical tests, such as the $t$-test, have nonstandard distributions. Hansen (1999) suggests a bootstrap method to simulate the asymptotic distribution of the following likelihood ratio test of $\mathrm{H}_{0}$ :

$$
L R_{0}=\left(R S S_{0}-R S S_{1}\right) / \hat{\sigma}^{2}
$$

Where $\mathrm{RSS}_{0}$, and $\mathrm{RSS}_{1}$ are the residual sum of squares under $H_{0}: \beta_{2}=0$, and $H_{1}: \beta_{2} \neq 0$, respectively; and $\hat{\sigma}^{2}$ is the residual variance under $\mathrm{H}_{1}$. In other words, $\mathrm{RSS}_{0}$ and $\mathrm{RSS}_{1}$ are the residual sum of squares for equation (1) without and with threshold effects, respectively. The asymptotic distribution of $L R_{0}$ is nonstandard and strictly dominates the $\chi^{2}$ distribution. The distribution of $L R_{0}$ depends in general on the moments of the sample; thus critical values cannot be tabulated. Hansen (1999) shows how to bootstrap the distribution of $L R_{0}$.

Before conducting any econometric analysis, the time series properties of the data must be investigated. We used: augmented Dickey_Fuller (ADF), Phillips_Perron(1988) ${ }^{1}$, (PP) and Kwiatkowski et al.(1992), $K P S S^{2}$ tests to assess the order of integration of the variables in equation1. In Table 1, results of the unit root tests on relevant variables have been reported. The findings of unit root tests suggest that all the variables are integrated of order zero. Therefore, any estimated relationship between the economic growth rate and oil revenues growth rate for Iran based on equation 1 would not be spurious. Moreover, statistical inference based on this specification would be valid.

1This version of the test is an extension of the Dickey_Fuller test, which makes a semi-parametric correction for autocorrelation and is more robust in the case of weakly autocorrelated and heteroskedastic regression residuals. According to Choi(1992) the Phillips_Perron tests $(P P)$ extension appear to be more powerful than the $A D F$ tests for aggregate data. For more details see Perron(1990).

2. The KPSS procedure assumes the univariate series can be decomposed into the sum of a deterministic trend, random walk and stationary disturbance and is based on a Lagrange Multiplier score testing principle. This test reverses the null and the alternative hypothesis. A finding favorable to a unit root in this case requires strong evidence against the null hypothesis of stationary. 
Table 1: Unit-Root Tests

\begin{tabular}{lllll}
\hline variable & $\boldsymbol{A D F}$ & $\boldsymbol{P P}$ & $\boldsymbol{K P S S}$ & Decision \\
\hline INF & $-3.19^{*}$ & $-3.26^{*}$ & 0.12 & $\mathrm{I}(0)$ \\
GDPGR & $-3.88^{* *}$ & $-3.92^{* *}$ & 0.24 & $\mathrm{I}(0)$ \\
INV & $-4.29^{* *}$ & $-3.81^{* *}$ & 0.13 & $\mathrm{I}(0)$ \\
OILREVGR & $-4.48^{* *}$ & $-4.48^{* *}$ & 0.16 & $\mathrm{I}(0)$ \\
\hline
\end{tabular}

Note: ${ }^{*}$ and ${ }^{* *}$ indicate rejection of the null of nonstationary at $10 \%$ and $1 \%$ significance level respectively. Empirical results indicate that the null hypothesis of unit-root is rejected in all cases at $10 \%$ significant level. The lag lengths for the $A D F$ and $P P$ tests are chosen by using SC's information criterion and Newey and West (1987) method respectively.

\section{Emprical Results}

Table 1 provides the estimation results of equation (1), for the linear specification (without threshold effect) and the nonlinear one (with threshold effect). The first step to explore the relation between the growth rate of oil revenues and economic growth is to test for the existence of a threshold effect in the relationship between real GDP growth and oil revenues using the likelihood ratio, $L R_{0}$, discussed above. This implies estimating equation (1) and computing the residual sum of squares (RSS) or $\mathrm{R}^{2}$ for different threshold levels of oil revenues growth $(K)$. The optimal threshold level is the one that makes RSS minimum or makes $\mathrm{R}^{2}$ maximum. It can be shown that the value of $\mathrm{R}^{2}$ is maximized when the oil revenues growth structural point is $22 \%$.The row $L R_{0}$ in Table 1 gives the observed value of the likelihood ratio. The significance levels have been computed using the bootstrap distributions of $L R_{0}{ }^{1}$. The null hypothesis of no threshold effects can be rejected at least at the 1 percent significance, strongly supporting the existence of threshold effects.

The column 1 in Table 1 provides the estimation results of equation (1), conditional on the threshold estimate. Recall that the existence of a threshold effect cannot be inferred simply from the significance level of the coefficient on the interactive term $(O I L R E V G R>K) *(O I L R E V G R-K)$ as the distribution of the $t$-statistic for this variable is highly nonstandard under the null hypothesis of no threshold effect. This is why the null hypothesis has been tested using the bootstrap distribution of the likelihood ratio $L R_{0}$. However, the distribution of the t-values of all explanatory variables retains their usual distribution under the alternative hypothesis of a threshold effect.

While oil revenues growth below its threshold level has a small positive effect on growth, oil revenues growth above the threshold level has a significant negative effect on growth. When the oil revenues growth is below the $22 \%$ threshold level, the impact of contemporaneous oil revenues growth (OILREVGR) on economic growth is positive and significant: $10 \%$ percent increase in the growth rate of oil revenues leads to an increase by 1.1\% in the non-oil GDP growth. On the other hand, the effect of contemporaneous oil revenues growth when it is greater than $\% 22$ turns out negative and significant: $10 \%$ percent increase in the oil revenues growth leads to a decrease by $-1.8 \%$ in the non-oil GDP growth. The sum of the two coefficients $(-0.07)$ means the annual growth rate of real GDP declines by $-0.7 \%$ when the growth rate of oil revenues jumps over the structural breakpoint.

When the equation is re-estimated without the threshold effects(the column 2 in Table 1), results for the linear model (misleadingly) indicate that the coefficient of oil revenues growth is positive and statistically significant at 10 percent, contrary to the resource curse effect. Indeed a $10 \%$ increase in contemporaneous oil revenues growth would increase economic growth by $1.2 \%$, a relatively strong positive impact when compared to the spline function results for a growth rate of oil revenues above the threshold $22 \%$. This suggests that not taking structural breaks into account will conceal the detrimental effects of oil revenues during extreme oil booms.

All of the (control) independent variables have the predicted sign. As expected, investment ratio has a positive and significant impact on economic growth. On average, an increase in the investment-GDP ratio of 10 percentage points will boost real GDP growth by 1.5 percentage points for non-linear specification and

2. For a more detailed discussion on the computation of the bootstrap distribution of LRo, see Hansen (1999). 
1.8 percentage points for linear specification. Also, the results, consistent with the economic theory, show a negative and significant relation between inflation and economic growth.

\begin{tabular}{lll}
\multicolumn{2}{l}{ Table1: Estimation of Model (sample1965-2005) } & (Dependent Variable: non-oil GDP growth) \\
\hline Independent Variables & Non-linear specification & $\begin{array}{l}\text { linear } \\
\text { specification }\end{array}$ \\
\hline OILREVGR(-1) & 0.06 & 0.10 \\
& $(4.23)^{\mathrm{a}}$ & $(1.99)^{\mathrm{b}}$ \\
OILREVGR & 0.11 & 0.12 \\
& $(3.43)^{\mathrm{a}}$ & $(3.11)^{\mathrm{a}}$ \\
$($ OILREVGR>K)*(OILREVGR-K) & -0.18 & - \\
& $(-4.20)^{\mathrm{a}}$ & \\
INV & 0.15 & 0.18 \\
& $(6.81)^{\mathrm{a}}$ & $(2.10)^{\mathrm{b}}$ \\
INF & -0.06 & -0.09 \\
& $(-6.21)^{\mathrm{a}}$ & $(-4.70)^{\mathrm{a}}$ \\
Optimal threshold(k) & $22 \%$ & - \\
LR $_{0}$ & $13.89^{\mathrm{a}}$ & - \\
Critical value $(1 \%)$ & 5.90 & - \\
$\mathrm{R}^{2}$ & 0.73 & 0.65 \\
F-statistics & $8.45^{\mathrm{a}}$ & $7.68^{\mathrm{a}}$ \\
\hline
\end{tabular}

Notes: The t-statistics, given between parentheses, are computed from White heteroskedasticityconsistent standard errors. The letters "a", "b" indicate statistical significance at 1 and 5 percent, respectively. The growth rate of a variable $\mathrm{x}$ is approximated by the first difference of the $\log$ of $\mathrm{x}, \operatorname{dlog}(\mathrm{x})$.

To check the stability of estimated parameters over the observation period and establish the usefulness of model with $K=0.22$, the cumulative sums (CUSUM), and CUSUM square test (CUSUMSQ) tests were conducted (Figure 1). These tests are based on cumulative sum of recursive residuals and squares of recursive residuals respectively and compare them with the $5 \%$ critical levels. Movements outside the critical lines suggest instability of the parameters. The CUSUM square test is particularly powerful tool to investigate the stability of estimated parameters if the shifts in the equation are systematic. Figure 1 show the CUSUM and CUSUM of squares for the estimated equation. Both of the tests confirm the absence of any breakpoint in the relationship between the two variables for Iran.

Figure1: stability tests

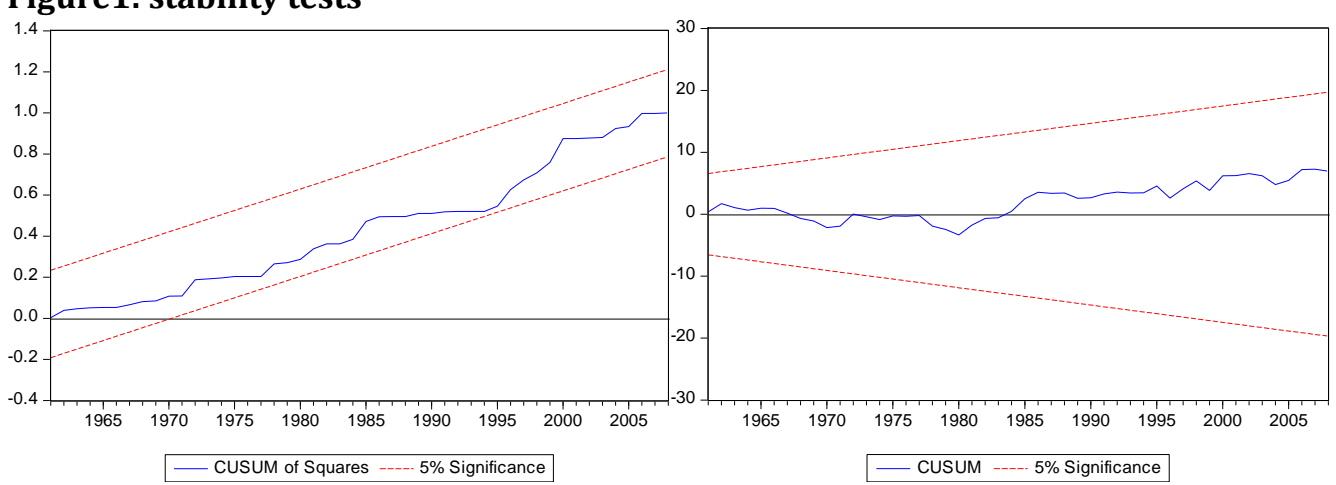

\section{Conclusion and Recommendations}

This paper examines the issue of the existence of threshold effects in the relationship between oil revenues and economic growth in Iran using annual data for the period 1959-2004. The results for the linear specification, consistent with the evidence found by Spatafora and Warner (1995), Yang and Lam (2007) and Berument and Ceylan (2007) suggest a positive relationship between growth and oil revenues. But, using the structural breakpoint methodology proved that this relation tend to be positive just below a threshold for the growth rate of oil revenues equal to $\% 22$. And after this point the effect tends to be negative. Indeed, the threshold level is taken to be the point at which oil exporting countries should begin to worry about oil revenues growth. So, although a modest boom can be a blessing, but an excessive boom (where oil revenues increase above the threshold level) turns to be a curse to the oil 
exporting countries. It seems that failure to allow to a nonlinear association between oil revenues and growth is responsible for such odd results in oil exporting countries.

The Iran economy suffering from a weak and undiversified economic base without stabilizing mechanisms in order to cushion shocks would be so vulnerable to boom-bust cycles, incurring costly instability. There is therefore a strong case for savings schemes, sound fiscal management and strong commitment to fiscal discipline to cushion the domestic economy from the sharp and unpredictable variations in oil prices and revenue. Policymakers must deploy institutional mechanisms to manage oil booms and busts through expenditure restraint, self-insurance, and diversification of the real sector. To achieve sustainable growth in the future, these countries must take policy measures that substantially enlarge and diversify their economic base. Moreover, to insulate the economy from oil revenue volatility requires de-linking fiscal expenditures from current revenue to undo the resource curse during extreme oil booms. So, an independent and transparent "oil revenue fund" (or, more generally, a "clear natural resource fund") is one such institutional mechanism for managing the oil revenues. By setting aside funds in a separate account, stabilization funds can provide a check against a natural tendency of governments to spend all of the resources at their disposal; and they can help ensure that the funds are spent on investments, so that the depletion of natural resources is offset by an increase in human and physical capital. Stabilization funds can also be used to reduce rent seeking particularly during extreme booms. By providing an open and transparent process for determining how the funds are used, stabilization funds can help prevent and diminish the deterrent effects of oil booms on economic growth. The effects of oil stabilization fund as well as institutional qualities on sustainable economic growth and stabilization can be suggested as future area of research.

Acknowledgements: This paper was funded by grant from the University of Tehran submitted to the author.

\section{References}

Aguiar, L \& Wen, Y. (2011), OPEC's Oil Exporting Strategy and Macroeconomic (In)Stability, Working Paper, Federal Reserve Bank, 2011-013A.

Auty, R. M. (2001). Resource Abundance and Economic Development. Oxford University Press, Oxford

Berument, H. \& Ceylan, N. B. (2007). The impact of oil price shocks on the economic growth of the selected MENA countries. Webpage: http://www.bilkent.edu.tr/ berument.

Bredin, D., Elder, J. \& Fountas, S. (2008), The Effects of Uncertainty about Oil Prices in G-7. Working paper, Banking \& Finance Subject Area UCD Business Schools, WP 08/08.

Choi, I. (1992). Effects of Data Aggregation on the Power of the Tests for a Unit Root. Economics Letters, $40,397-401$.

Devlin, J. \& Lewin, M. (2004). Managing Oil Booms and Busts in Developing Countries, Draft Chapter for: Managing Volatility and Crises, A Practitioner's Guide.

Frederick, V. D. P (2010), Aggressive Oil Extraction and Precautionary Saving: Coping with Volatility, Cesifo Working Paper, 3038.

Gelb, A. H. (1988). Windfall Gains: Blessing or Curse? New York: Oxford University Press.

Gylfason, T., Herbertsson T. T. \& Zoega, G. (1999). A Mixed Blessing: Natural Resources and Economic Growth. Macroeconomic Dynamics, 3, 204-225.

Hansen, B. (1999). Threshold Effects in Non-Dynamic Panels: Estimation, Testing, and Inference. Journal of Econometrics, 93(2), 345-68.

Hausmann, R. \& Rigobon, R. (2003). An alternative explanation of the resource curse. In: Jeffrey Davis, Rolando Ossowski, and Annalisa Fedelino, eds., Fiscal Policy Formulation and Implementation in Oil-Producing Countries. Washington, D.C. International Monetary Fund.

Karl, T. L., (1997). The Paradox of Plenty: Oil Booms and Petro States. University of California Press, Berkeley, CA.

Kwiatkowski, D., Phillips, P. C. B., Schmidt, P. \& Shin, Y. (1992). Testing the null hypothesis of stationary against the alternative of a unit root: How sure are we that economic time series have a unit root? Journal of Econometrics, 54, 159-178.

Levine, R. \& Renelt, D. (1992). A Sensitivity Analysis of Cross-Country Growth Regressions. American Economic Review, 82, 942-63.

Mendoza, O. \& Vera, D. (2010). the Asymmetric Effects of Oil Shocks on an Oil-exporting Economy, Cuadernos De Economia, 47, 3-13. 
Mohammadi, H. \& JahanParvar, M. R. (2010). Oil prices and exchange rates in oil-exporting countries: evidence from TAR and M-TAR models. Journal of Economics and Finance, 1-14-14.

Nakov, A \& Pescatori, A. (2010). Oil and the Great Moderation. The Economic Journal, 120(543), 131-156.

Phillips, P. C. B. \& Perron, P. (1988). Testing for a unit root. Biometrica, 75, 335-346.

Pineda, J. \& Rodriguez, F. (2010). Curse or Blessing? Natural Resources and Human Development, United Nations Development Program, Human Development Reports, Research Paper 2010/04.

Romer, D. (1990). Endogenous technological change. Journal of Political Economy, 98, 71-102.

Sachs, J. D. \& Warner, A. M. (1995). Natural Resource Abundance and Economic Growth. NBER Working, 5398.

Sachs, J. D. \& Warner, A. M. (1997). Sources of Slow Growth in African Economies. Journal of African Economies, 6 (3), 335-76.

Sachs, J. D. \& Warner, A. M. (2001). The Curse of Natural Resources. European Economic Review, 45, 827838.

Sala-i-Martin, X. \& Subramanian, A. (2003). Addressing the Natural Resource Curse: An Illustration from Nigeria. NBER Working Paper, 9804.

Spatafora, N. \& Warner, A. M. (1995). Macroeconomic Effects of Terms-of-Trades Shocks: the Case of Oil Exporting Countries. Policy Research Working Paper, 1410, the World Bank.

Temple, J. (1999). The New Growth Evidence. Journal of Economic Literature, 37, 112-156.

Thorsten, B. (2010). Finance and Oil is there a resource curse in financial development? European Banking Center Discussion, 2011-004.

Trung, L. V. \& Vinh, N. T. T. (2011). The impact of oil prices, real effective exchange rate and inflation on economic activity: Novel evidence for Vietnam, Discussion Paper Series, RIEB, Kobe University, DP 2011-09.

Yang, B. \& Lam, Y. (2007). Resource booms and economic development: the time series dynamics for 17 oil-rich countries. Applied Economics Letters, 15(13-15), 1011-1014. 